\title{
Side Effects of Vincristine and L-Asparaginase in Patients with Acute Lymphoblastic Leukemia in a Mexican Pediatric Hospital
}

\author{
Mario I. Ortiz ${ }^{1,2 \#}$, Sandra Rivera-Roldán ${ }^{3,4}$, Marco A. Escamilla-Acosta ${ }^{3}$, \\ Georgina Romo-Hernández ${ }^{3}$, Héctor A. Ponce-Monter ${ }^{1}$, Rita Escárcega-Ángeles ${ }^{3,4}$ \\ ${ }^{1}$ Área Académica de Medicina, Instituto de Ciencias de la Salud, Universidad Autónoma del Estado de Hidalgo, Pachuca, Mexico; \\ ${ }^{2}$ Graduate Coordination, Universidad del Futbol y Ciencias del Deporte, San Agustín Tlaxiaca, Mexico; ${ }^{3}$ Hospital del Niño DIF \\ Hidalgo, Pachuca, Mexico; ${ }^{4}$ Área Académica de Farmacia, Instituto de Ciencias de la Salud, Universidad Autónoma del Estado de \\ Hidalgo, Pachuca, Mexico. \\ Email: "mario_i_ortiz@hotmail.com
}

Received April $7^{\text {th }}, 2013$; revised May $10^{\text {th }}, 2013$; accepted May $19^{\text {th }}, 2013$

Copyright (C) 2013 Mario I. Ortiz et al. This is an open access article distributed under the Creative Commons Attribution License, which permits unrestricted use, distribution, and reproduction in any medium, provided the original work is properly cited.

\begin{abstract}
Background: The treatment used to combat acute lymphoblastic leukemia (ALL) is multidrug; therefore it is important to use active pharmacovigilance to detect, assess and analyze the likely adverse reactions which may occur during the same period. Objective: To determine the frequency of adverse reactions to chemotherapeutic drugs in children with ALL. Material and Methods: Intensive pharmacovigilance was used to record the reports of adverse reactions to vincristine, L-asparaginase and the vincristine-L-asparaginase combination in children with ALL in a paediatric hospital. For each notification, the adverse reactions were analyzed in order to verify causality. Results: Forty patients were evaluated. Twenty children were female $(50.0 \%)$ and 20 were male $(50 \%)$. The children had a mean age, weight and height ( \pm standard deviation: SD) of $8.1( \pm 3.4)$ years, $31.4( \pm 13.9) \mathrm{kg}$ and $1.3( \pm 0.2) \mathrm{m}$, respectively. Vincristine was administered to 19 patients, vincristine plus L-asparaginase were given to 19 patients and only 2 patients used L-asparaginase. One-hundred-ninety adverse reactions were detected in the patients, with an average $( \pm \mathrm{SD})$ of 4.8 $( \pm 2.6)$. Ondansetron was the drug administered for the treating of nausea and vomiting. One hundred eighty-one (95.3\%) adverse reactions were identified as "definite", $5(2.6 \%)$ as "probable" and $4(2.1 \%)$ as "doubtful". Conclusions: There is a high incidence of adverse reactions by the administration of vincristine and L-asparaginase; the reactions of highest incidence were: nausea, vomiting, neutropenia, diarrhea, constipation, mucositis, headache, and abdominal pain. It is important to promote the detection, collection, reporting, assessment and treatment of ARD's in children. It is necessary to promote the conduct further studies on pharmacovigilance with this type of treatments and to increase the duration of the studies.
\end{abstract}

Keywords: Pharmacovigilance; Acute Lymphoblastic Leukemia; Vincristine; L-Asparaginase; Children

\section{Introduction}

Cancer is a term that refers to diseases in which abnormal cells divide uncontrollably and can invade various tissues nearby. Cancer cells can also spread to other parts of the body through blood and the lymphatic system. Leukemia is a kind of cancer that starts in blood-forming tissues such as bone marrow and causes large numbers of abnormal blood cells to be produced and enter the blood stream. Acute lymphoblastic leukemia (ALL) reflects a

*The authors declare no conflict of interest.

"Corresponding author. heterogeneous group of diseases that are characterized by variability in immunophenotype, cytogenetics and clinical features [1]. ALL is the most common pediatric malignancy. The world incidence of ALL varies between 20 and 35 cases per million [2], whereas the incidence of ALL in Mexican population is greater than 40 cases per million [2-4]. Therapy for childhood ALL involve the induction, central nervous system (CNS) prophylaxis, intensification and maintenance phases. In general, the induction phase includes the following chemotherapeutic agents: glucocorticoid, vincristine, L-asparaginase and/or 
an anthracycline. The prophylaxis of CNS usually uses early intensive intrathecal therapy with methotrexate, hydrocortisone and cytarabine [5]. The Intensification phase (consolidation) is designed to eliminate residual leukemia and includes a readministration of the initial therapy 24 weeks to 3 months following remission. To enhance continuation of remission, children with ALL receive maintenance chemotherapy for $2-2.5$ years following consolidation. Weekly doses of methotrexate and daily mercaptopurine are standard, with intermittent pulses of vincristine and a glucocorticoid administered in most settings [6]. Chemotherapy is an important modality in the treatment of ALL. However, chemotherapyinduced damage to normal cells results in chemotherapy toxicities and side effects. In general, this toxicity can be seen in those actively dividing tissues such as bone marrow, hair follicles and gastrointestinal mucosa. Therefore, strict pharmacovigilance is required by the presence of adverse reactions.

Pharmacovigilance is defined as the science and activities concerned with the detection, assessment, understanding and prevention of adverse reactions to medicines (i.e. adverse drug reactions or ADRs). The ultimate goal of this activity is to improve the safe and rational use of medicines, thereby improving patient care and public health $[7,8]$. In the chemotherapy, the pharmacovigilance is used to identify new information about adverse reactions and prevent damage to the patients [7, 8]. Large amounts of pharmacovigilance data about chemotherapeutic drugs are dispersed throughout research papers in the literature and pharmaceutical industry. However, reports about side effects by chemotherapy in Mexican children are very scarce and limited $[9,10]$. Therefore, the present study aimed to monitor notifications of suspected AR produced by vincristine and Lasparaginase in patients with ALL in a Mexican pediatric hospital.

\section{Methods}

The aim of this study was to determine the frequency of suspicion of adverse reactions to vincristine and L-asparaginase. A single-center, prospective, longitudinal and analytic trial was conducted at the Hospital del Niño DIF Hidalgo, Mexico from January to July 2012. The Ethics and Investigation Committees (Hospital del Niño DIF Hidalgo, Mexico) approved the study protocol, and the study was performed according to the guidelines delineated by the Declaration of Helsinki.

Participants who met the following criteria were included: patients with ALL, ranging in age from 2 to 15 years, both genders and whose parents accepted to participate in the study.

The Mexican paediatric hospital where the study was carried out is an adolescent and children's hospital that cares for newborn patients to patients 17 years of age. The researchers explained the objective of the study to the children and their parents, obtained written consent and gathered baseline information of the medical history. Intensive pharmacovigilance was realized while patients were receiving vincristine and/or L-asparaginase in remission induction phase; data were recorded on a special format for reporting suspicious of adverse reaction. For each notification, the adverse reactions were analyzed in order to verify causality. In this study an expert panel applied the Naranjo algorithm [11]. This algorithm classifies the reactions into four types: Definite, probable, possible, and doubtful.

Data were entered into a computerized database. SPSS version 17 for Windows (SPSS Inc., Chicago, IL, USA) was used for descriptive statistical analyses. Data are shown as frequencies, percentages and mean \pm standard deviation of the mean (SD).

\section{Results}

A total of 40 patients were evaluated from January to July 2012. Twenty children were female (50.0\%), and 20 were male $(50.0 \%)$. Anthropometric data of the patients (age, weight, height, body mass index, weight for age and height for age) are displayed in the Table 1. Vincristine was administered to 19 patients, vincristine plus L-asparaginase were given to 19 patients and only 2 patients used L-asparaginase in the study period. The drug dosages used were: vincristine to $1.5 \mathrm{mg} / \mathrm{m}^{2}$ and L-asparaginase to $10,000 \mathrm{U} / \mathrm{m}^{2}$. Vincristine was diluted in 20 $\mathrm{mL}$ saline solution $(0.9 \%)$ and it was administered in intravenous bolus in 4 to 5 minutes. L-asparaginase was not diluted and it was administered in intramuscular bolus in 60 to 90 seconds. A total of 190 adverse reactions were detected in the patients (Table 2), with an average $( \pm \mathrm{SD})$ of $4.8( \pm 2.6)$ ADRs/child (range: 0 - 14); 120 of these ADRs (63.2\%) were produced by the vincristineL-asparaginase combination (range: $0-11$ and mean \pm $\mathrm{SD}$ of $6.3 \pm 2.2), 60$ ARDs $(31.6 \%)$ were induced by vincristine (range: $0-14$ and mean \pm SD of $3.16 \pm 1.9$ ) and 10 ARDs (5.2\%) were made by L-asparaginase (range: $1-2$ and mean $\pm \mathrm{SD}$ of $5.0 \pm 2.8$ ). Ondansetron was the drug administered for the treating of nausea and vomiting $(84.2 \%$ in the vincristine group, $73 \%$ in the vincristine + L-asparaginase group and $100 \%$ in the Lasparaginase group). Pharmacotherapy administered 1 or 2 weeks before the administration of vincristine and/or $\mathrm{L}$-asparaginase is displays in the Table 3.

According to the relationship between the drug administration and the presence of adverse reactions, these were evaluated and analyzed by the Naranjo modified algorithm, where 181 (95.3\%) were identified as "definite", 
in a Mexican Pediatric Hospital

Table 1. Anthropometric data of the patients.

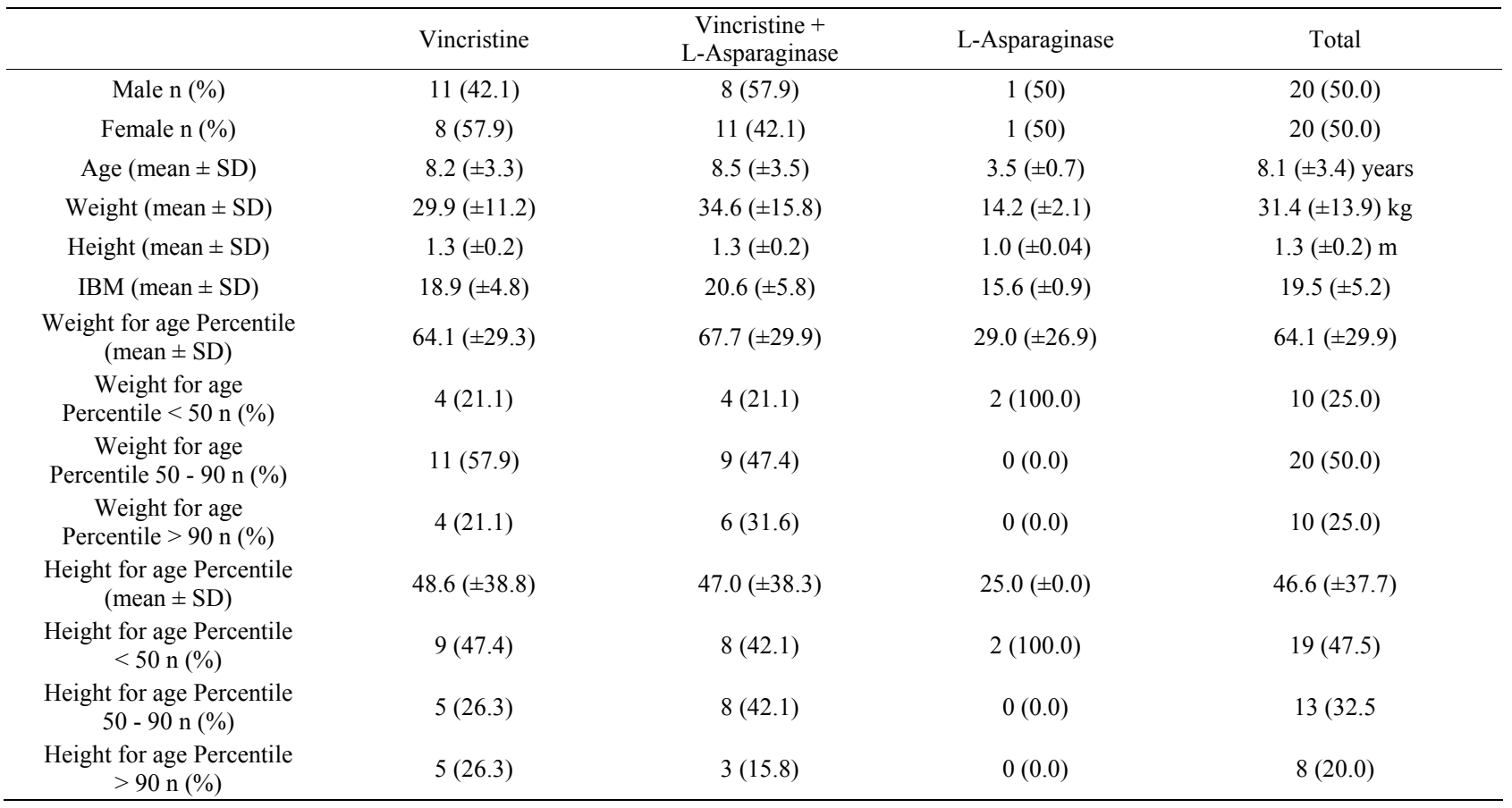

Table 2. Adverse reactions detected in the patients with the drugs administered.

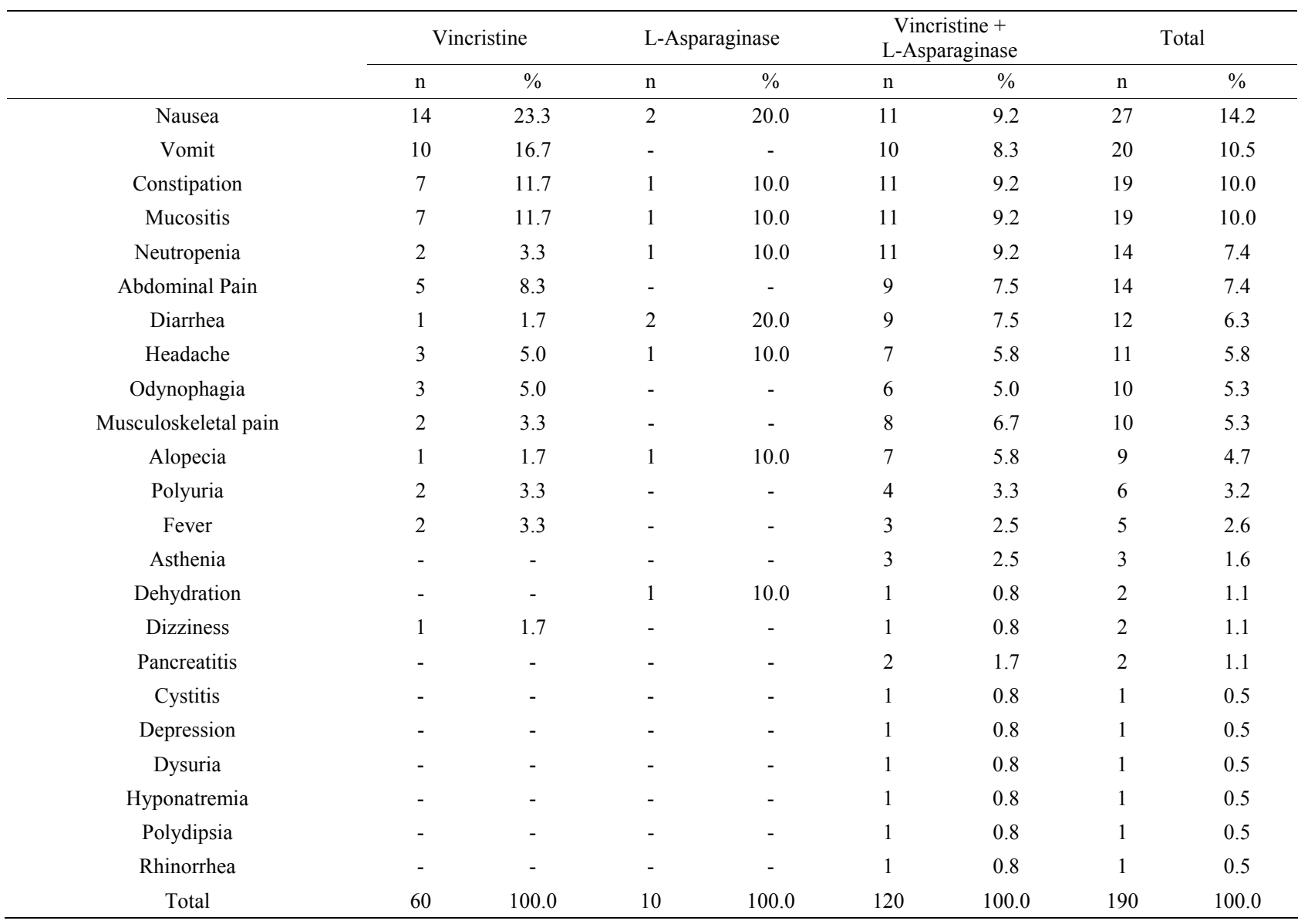


Table 3. Drugs used by the patients from 1 to 2 weeks before the administration of vincristine and/or L-asparaginase.

\begin{tabular}{|c|c|}
\hline Patient & Vincristine with concomitant drugs \\
\hline 1 & Methotrexate and ondansetron \\
\hline 2 & Ondansetron \\
\hline 3 & Ondansetron \\
\hline 4 & Ondansetron \\
\hline 5 & Ondansetron \\
\hline 6 & Ondansetron \\
\hline 7 & Ondansetron \\
\hline 8 & Propranolol, captopril \\
\hline 9 & Mercaptopurine \\
\hline 10 & Methotrexate, ondansetron \\
\hline 11 & Methotrexate, ondansetron \\
\hline 12 & Methotrexate, ondansetron, folinic acid \\
\hline 13 & Mercaptopurine \\
\hline 14 & Ondansetron, cytarabine, etoposide \\
\hline 15 & Arabinoside, ondansetron \\
\hline 16 & Arabinoside, ondansetron, doxorubicin \\
\hline 17 & Ondansetron \\
\hline 18 & Ondansetron \\
\hline 19 & Ondansetron \\
\hline Patient & Vincristine + L-asparaginase with concomitant drugs \\
\hline 1 & Mercaptopurine \\
\hline 2 & Ondansetron \\
\hline 3 & Mercaptopurine, methotrexate, ondansetron \\
\hline 4 & Ondansetron, cytarabine, methotrexate \\
\hline 5 & Ondansetron \\
\hline 6 & Doxorubicin, ondansetron, dexrazoxane \\
\hline 7 & Doxorubicin, ondansetron, methotrexate, etoposide \\
\hline 8 & Ondansetron, dexrazoxane, doxorubicin, cytarabine, etoposide \\
\hline 9 & Mercaptopurine, methotrexate, ondansetron \\
\hline 10 & Trimethoprim-sulfamethoxazole, methotrexate, mercaptopurine, folinic acid \\
\hline 11 & Allopurinol, etoposide, ondansetron, arabinoside \\
\hline 12 & Ceftriaxone, allopurinol, methotrexate, ondansetron, folinic acid \\
\hline 13 & Doxorubicin, ondansetron, dexrazoxane \\
\hline 14 & Methotrexate, mercaptopurine, prednisone \\
\hline 15 & Ondansetron, cytarabine \\
\hline 16 & Methotrexate, mercaptopurine, prednisone \\
\hline 17 & Captopril, hydrochlorothiazide, methotrexate, ondansetron, folinic acid \\
\hline 18 & Methotrexate, ondansetron, dexrazoxane, doxorubicin \\
\hline 19 & None \\
\hline Patient & L-asparaginase with concomitant drugs \\
\hline 1 & Methotrexate, cetirizine, ondansetron, folinic acid \\
\hline 2 & Methotrexate, mercaptopurine, ondansetron \\
\hline
\end{tabular}


$5(2.6 \%)$ as "probable" and $4(2.1 \%)$ as "doubtful".

During the administration of vincristine, $55 \%$ of adverse reactions were mild and $45 \%$ were moderate. In the group with vincristine and L-asparaginase combination, $41.8 \%$ of adverse reactions were mild, $57.4 \%$ were moderate and only $0.8 \%$ were severe. After the administration of L-asparaginase, $30 \%$ of the reactions were mild and $70 \%$ were moderate.

In the vincristine group, in $13(68.4 \%)$ patients the ARs did not let sequelaes and in $6(31.6 \%)$ patients the ARs let mild sequelaes, but recovered. In the vincristine plus L-asparaginase group, in $15(78.9 \%)$ patients the ARs did not let sequelaes and in $4(21.1 \%)$ patients the ARs let mild sequelaes, but recovered. In 1 patient the ARs (50\%) to L-asparaginase did not let sequelaes and in $1(50 \%)$ patient the AR let mild sequelaes, but recovered. No patient died during the study period.

\section{Discussion}

During the study we could demonstrate that nausea and vomit were the main adverse reactions to both vincristine and L-asparaginase. Nausea and vomiting are the most important side effects associated with chemotherapy in children with cancer [12-15]. Nausea and vomiting are also responsible for the poor treatment compliance. There are three distinct syndromes, but related, of nausea and vomit induced by chemotherapy, which can be classified according to their occurrence. Acute: it is seen in the first 24 hours after treatment has started. The incidence and severity vary widely. Delayed: it occurs in $20 \%-80 \%$ of patients 24 hours after chemotherapy, lasting $1-7$ days, with peak intensity usually on the third day. In $25 \%$ of pediatric patients occur anticipatory nausea and vomiting (also called conditioning or psychological), indicating that symptoms appear prior to the therapeutic administration of chemotherapy. This phenomenon is due to a conditioned response to the effects of prior chemotherapy and associated environmental stimuli such as location, smells, tastes, sensations previously experienced by patients receiving chemotherapy [12-15]. It is important to note that vincristine and Lasparaginase are classified as drugs with minimal emetogenic potential $(<10 \%)$ [16]. However, it has been mentioned that the classifications have limitations because the imprecise and inconsistent ways in which reports of nausea and vomiting have been recorded in the most therapeutic studies [16]. Therefore, the high prevalence of nausea and vomiting observed in our study could be due to two possible causes: the chemotherapy individual or combined or the concomitant medications observed in Table 3. Likewise, results show that nausea and vomiting are being inadequately treated. Hence, the medical and nursing staff should be extra careful in dealing with these adverse reactions.

Constipation, mucositis and neutropenia were also common in our patients. These reports are comparable with reports of the literature [17-20]. Pancreatitis has been reported in about one fifth of pediatric patients receiving L-asparaginase $[21,22]$. In fact, the combination of vinca alkaloids and L-asparaginase therapy has been linked to pancreatitis in humans [23]. In our study, 2 patients experienced mild pancreatitis. These patients were receiving vincristine plus L-asparaginase. There are few reports of the association of pancreatitis and the use of vincristine alone [24]. It has been demonstrated in mice, that vinca alkaloids alone are able to cause degeneration of acinar cells of the pancreas [25]. However, vincristine administered to dogs did not cause clinical or subclinical pancreatitis [26]. Therefore, care should be taken on the possible occurrence of this reaction when patients are receiving the vincristine-L-asparaginase combination.

Cystitis was a side effect identified in a patient by the use of vincristine with L-asparaginase. There is a report in the literature about a clinical case of cystitis in a patient with treatment of advanced seminoma with cyclophosphamide, vincristine and carboplatin [27]. However, there are in general few reports of cystitis caused by vincristine and/or L-asparaginase. It is important to note that this AR can be preventable in most cases, since you need to hydrate the patient before and after the drug administration in order to prevent accumulation of drug at the urinary bladder. For this reason, it is possible that the patient was dehydrated at the time of administration. The World Health Organization (WHO) published an alert about the fatal results by the vincristine administration by spinal route [28]. The WHO suggests the administration of vincristine in a diluted volume (e.g. $50 \mathrm{~mL}$ normal saline) via a minibag. In our case, vincristine was diluted in $20 \mathrm{~mL}$ saline solution $(0.9 \%)$ and it was administered in intravenous bolus in 4 minutes.

Vincristine and other anti-cancer drugs are well reported to exert direct and indirect effects on sensory nerves to induce peripheral neuropathy characterized by progressive motor, sensory, and autonomic involvement [29]. There are reports indicating that vincristine-induced neuropathy depend of increased sensitivity and/or variability in the vincristine pharmacokinetic [30]. In the last case, pharmacokinetic studies reported a 19-fold difference in the area under the concentration time curve in children [31]. Likewise, a recent study did not found a correlation between vincristine clearance, vincristine neurotoxicity, age, sex or concomitant steroid therapy [32]. Therefore, it is possible to find fluctuations in the incidence of vincristine-induced neuropathy in children. That was observed in the present study, where neuropathy was found only in $25 \%$ of patients. Henceforth, the docu- 
mentation of factors influencing the vincristine-induced neuropathy is necessary.

Coagulation defects can be produced by vincristine and L-asparaginase in a few patients [33,34]. These effects are due to vascular defects, thrombocytopenia, and platelet dysfunction. Bleeding or coagulation alterations were not identified in the preset study. We do not have a real answer to this pattern. Probably these alterations were presented in the patients before or after the evaluation period or these alterations were avoided by the concomitant drugs administration (folinic acid or corticosteroids). Therefore, pharmacovigilance should be made from the admission to the discharge of the patient.

Most adverse reactions reported were known. However, polydipsia was presented in a patient with the vincristine and L-asparaginase combination. The same patient presented odynophagia, mucositis, diarrhea, vomit and dehydration. In this case, polydipsia was rated as mild and classified as "doubtful" according to the Naranjo algorithm. It is probable that the dehydration of the patient could have caused the presence of polydipsia.

As mentioned in the literature, there are several drug interactions that may potentiate the occurrence of adverse reactions as in the case of concomitant use with other anticancer agents, antibiotic, steroids, and other drugs that can produce the same adverse reactions. For this reason, care must be taken in the presentation of adverse reactions when using polypharmacy in patients with cancer.

Fortunately, most of the ARD's observed with the use of these two drugs left no sequelae in the patients, but we should not reduce the monitoring of adverse reactions to avoid considerable complications.

\section{Conclusions}

It can be concluded after analysis of data that there is a high incidence of adverse reactions by the administration of vincristine and L-asparaginase; the most common being nausea, vomiting, mucositis, neutropenia, diarrhea, and constipation; ranging from mild to moderate. The present study provides strong evidence to promote the detection, collection, reporting, assessment and treatment of ARD's in children. It is necessary to promote the conduct further studies on pharmacovigilance with this type of treatments and to increase the duration of the studies.

MIO, SRR, MAEA, GRH, HAPM and REA participated in the design of the study and performed the statistical analysis. MIO, SRR, MAEA, GRH, HAPM and REA conceived of the study, and participated in its design and coordination and helped to draft the manuscript. All authors read and approved the final manuscript.

\section{REFERENCES}

[1] J. F. Margolin, K. R. Rabi, C. P. Steuber and D. G. Poplack, "Acute Lymphoblastic Leukemia," In: P. A. Pizzo and D. G. Poplack, Eds., Principles and Practice of Pediatric Oncology, Lippincott Williams \& Wilkins, Philadelphia, 2011, pp. 518-565.

[2] D. W. Parkin and C. A. Stiller, "Childhood Cancer in Developing Countries: Environmental Factors," International Journal of Pediatric Hematology/Oncology, Vol. 2, 1995, pp. 411-417.

[3] M. J. Matasar, E. K. Ritchie, N. Consedine, C. Magai and A. I. Neugut, "Incidence Rates of the Major Leukemia Subtypes among US Hispanics, Blacks, and Non-Hispanic Whites," Leukemi \& Lymphoma, Vol. 47, No. 11, 2006, pp. 2365-2370. doi:10.1080/10428190600799888

[4] J. M. Mejía-Aranguré, M. Bonilla, R. Lorenzana, S. Juárez-Ocaña, G. de Reyes, M. L. Pérez-Saldivar, G. González-Miranda, R. Bernáldez-Ríos, A. Ortiz-Fernández, M. Ortega-Alvarez, C. Martínez-García Mdel and A. Fajardo-Gutiérrez, "Incidence of Leukemias in Children from El Salvador and Mexico City between 1996 and 2000: Population-Based Data," BMC Cancer, Vol. 5, 2005, p. 33. doi:10.1186/1471-2407-5-33

[5] C. H. Pui, D. Campana, D. Pei, W. P. Bowman, J. T. Sandlund, S. C. Kaste, R. C. Ribeiro, J. E. Rubnitz, S. C. Raimondi, M. Onciu, E. Coustan-Smith, L. E. Kun, S. Jeha, C. Cheng, S. C. Howard, V. Simmons, A. Bayles, M. L. Metzger, J. M. Boyett, W. Leung, R. Handgretinger, J. R. Downing, W. E. Evans and M. V. Relling, "Treating Childhood Acute Lymphoblastic Leukemia without Cranial Irradiation," The New England Journal of Medicine, Vol. 360, No. 26, 2009, pp. 2730-2741.

doi:10.1056/NEJMoa0900386

[6] C. H. Pui, L. L. Robison and A. T. Look, "Acute Lymphoblastic Leukaemia," Lancet, Vol. 371, No. 9617, 2008, pp. 1030-1043. doi:10.1016/S0140-6736(08)60457-2

[7] WHO, "Looking at the Pharmacovigilance: Ensuring the Safe Use of Medicines. WHO Policy Perspectives on Medicines," World Health Organization, Geneva, 2004. http://www.whqlibdoc.who.int/hq/2004/WHO_EDM 200 4.8.pdf

[8] G. Jeetu and G. Anusha, "Pharmacovigilance: A Worldwide Master Key for Drug Safety Monitoring," Journal of Young Pharmacists: JYP, Vol. 2, No. 3, 2010, pp. 315320. doi:10.4103/0975-1483.66802

[9] G. J. Ruiz-Argüelles, L. N. Coconi-Linares, J. GarcésEisele and V. Reyes-Núñez, "Methotrexate-Induced Mucositis in Acute Leukemia Patients Is Not Associated with the MTHFR 677T Allele in Mexico," Hematology, Vol. 12, No. 5, 2007, pp. 387-391. doi:10.1080/10245330701448479

[10] L. I. Castro-Pastrana and B. C. Carleton, "Improving Pediatric Drug Safety: Need for More Efficient Clinical Translation of Pharmacovigilance Knowledge," Journal of Population Therapeutics and Clinical Pharmacology, Vol. 18, No. 1, 2011, pp. e76-e88.

[11] C. A. Naranjo, U. Busto, E. M. Sellers, P. Sandor, I. Ruiz, E. A. Roberts, E. Janecek, C. Domecq and D. J. Green- 
blatt, "A Method for Estimating the Probability of Adverse Drug Reactions," Clinical Pharmacology and Therapeutics, Vol. 30, No. 2, 1981, pp. 239-245. doi:10.1038/clpt.1981.154

[12] D. G. Warr, "Chemotherapy- and Cancer-Related Nausea and Vomiting," Current Oncology, Vol. 15, Supplement 1, 2008, pp. S4-S9. doi:10.3747/co.2008.171

[13] J. Herrstedt, J. M. Koeller, F. Roila, P. J. Hesketh, D. Warr, C. Rittenberg and M. Dicato, "Acute Emesis: Moderately Emetogenic Chemotherapy," Support Care Cancer, Vol. 13, No. 2, 2005, pp. 97-103. doi:10.1007/s00520-004-0701-7

[14] F. Roila, D. Warr, R. A. Clark-Snow, M. Tonato, R. J. Gralla, L. H. Einhorn and J. Herrstedt, "Delayed Emesis: Moderately Emetogenic Chemotherapy," Support Care Cancer, Vol. 13, No. 2, 2005, pp. 104-108. doi:10.1007/s00520-004-0700-8

[15] M. S. Aapro, A. Molassiotis and I. Olver, "Anticipatory Nausea and Vomiting," Support Care Cancer, Vol. 13, No. 2, 2005, pp. 117-121. doi:10.1007/s00520-004-0745-8

[16] F. Roila, J. Herrstedt, M. Aapro, R. J. Gralla, L. H. Einhorn, E. Ballatori, E. Bria, R. A. Clark-Snow, B. T. Espersen, P. Feyer, S. M. Grunberg, P. J. Hesketh, K. Jordan, M. G. Kris, E. Maranzano, A. Molassiotis, G. Morrow, I. Olver, B. L. Rapoport, C. Rittenberg, M. Saito, M. Tonato and D. Warr, "ESMO/MASCC Guidelines Working Group. Guideline Update for MASCC and ESMO in the Prevention of Chemotherapy- and Radiotherapy-Induced Nausea and Vomiting: Results of the Perugia Consensus Conference," Annals of Oncology, Vol. 21, Supplement 5, 2010, pp. v232-v243.

doi:10.1093/annonc/mdq194

[17] F. Turpin, M. Tubiana-Hulin, L. Meeus, A. Goupil, J. Berlie and B. Clavel, "Complications of Antitumor and Antileukemic Chemotherapy," La Semaine des Hôpitaux, Vol. 58, No. 36, 1982, pp. 2047-2057.

[18] S. L. Figliolia, D. T. Oliveira, M. C. Pereira, J. R. Lauris, A. R. Maurício, D. T. Oliveira and M. L. Mello de Andrea, "Oral Mucositis in Acute Lymphoblastic Leukaemia: Analysis of 169 Paediatric Patients," Oral Diseases, Vol. 14, No. 8, 2008, pp. 761-766. doi:10.1111/j.1601-0825.2008.01468.x

[19] S. Yilmaz, H. Oren, F. Demircioğlu and G. Irken, "Assessment of Febrile Neutropenia Episodes in Children with Acute Leukemia Treated with BFM Protocols," Pediatric Hematology and Oncology, Vol. 25, No. 3, 2008, pp. 195-204. doi:10.1080/08880010801938231

[20] M. Diezi, A. Nydegger, E. R. Di Paolo, H. Kuchler and M. Beck-Popovic, "Vincristine and Intestinal Pseudo-Obstruction in Children: Report of 5 Cases, Literature Review, and Suggested Management," Journal of Pediatric Hematology/Oncology, Vol. 32, No. 4, 2010, pp. e126e130. doi:10.1097/MPH.0b013e3181d7742f

[21] R. Pieters, S. P. Hunger, J. Boos, C. Rizzari, L. Silverman, A. Baruchel, N. Goekbuget, M. Schrappe and C. H. Pui, "L-Asparaginase Treatment in Acute Lymphoblastic Leukemia: A Focus on Erwinia Asparaginase," Cancer, Vol.
117, No. 2, 2011, pp. 238-249.

doi:10.1002/cncr.25489

[22] B. Sikorska-Fic, E. Stańczak, M. Matysiak and A. Kamiński, "Acute Pancreatitis during Chemotherapy of Acute Lymphoblastic Leukaemia Complicated with Pseudocyst," Medycyna Wieku Rozwojowego, Vol. 12, No. 4, 2008, pp. 1051-1055.

[23] D. Schuler, R. Koós, T. Révész, I. Virág and I. Gálfi, "LAsparaginase Therapy and Its Complications in Acute Lymphoid Leukaemia and Generalized Lymphosarcoma," Haematologia (Budap), Vol. 10, No. 2, 1976, pp. 205211.

[24] J. S. Withycombe, J. E. Post-White, J. L. Meza, R. G. Hawks, L. M. Smith, N. Sacks and N. L. Seibel, "Weight Patterns in Children with Higher Risk ALL: A Report from the Children's Oncology Group (COG) for CCG 1961," Pediatr Blood \& Cancer, Vol. 53, No. 7, 2009, pp. 1249-1254. doi:10.1002/pbc. 22237

[25] T. J. Nevalainen, "Cytotoxicity of Vinblastine and Vincristine to Pancreatic Acinar Cells," Virchows Archives B: Cell Pathology Including Molecular Pathology, Vol. 18, No. 2, 1975, pp. 119-127.

[26] Z. Wright, J. Steiner, J. Suchodolski, K. Rogers, C. Barton and M. Brown, "A Pilot Study Evaluating Changes in Pancreatic Lipase Immunoreactivity Concentrations in Canines Treated with L-Asparaginase (ASNase), Vincristine, or Both for Lymphoma," Canadian Journal of Veterinary Research, Vol. 73, No. 2, 2009, pp. 103-110.

[27] S. Sleijfer, P. H. Willemse, E. G. de Vries, W. T. van der Graaf, H. Schraffordt Koops and N. H. Mulder, "Treatment of Advanced Seminoma with Cyclophosphamide, Vincristine and Carboplatin on an Outpatient Basis," British Journal of Cancer, Vol. 74, No. 6, 1996, pp. 947950. doi:10.1038/bjc.1996.462

[28] World Health Organization, "Information Exchange System," Alert No. 115, 2007.

http://www.who.int/patientsafety/highlights/PS_alert_1b1 5_ vincristine.pdf

[29] A. S. Jaggi and N. Singh, "Mechanisms in Cancer-Chemotherapeutic Drugs-Induced Peripheral Neuropathy," Toxicology, Vol. 291, No. 1-3, 2012, pp. 1-9. doi:10.1016/j.tox.2011.10.019

[30] A. Egbelakin, M. J. Ferguson, E. A. MacGill, A. S. Lehmann, A. R. Topletz, S. K. Quinney, L. Li, K. C. McCammack, S. D. Hall and J. L. Renbarger, "Increased Risk of Vincristine Neurotoxicity Associated with Low CYP3A5 Expression Genotype in Children with Acute Lymphoblastic Leukemia," Pediatric Blood \& Cancer, Vol. 56, No. 3, 2011, pp. 361-367. doi: $10.1002 /$ pbc. 22845

[31] B. M. Frost, G. Lönnerholm, P. Koopmans, J. Abrahamsson, M. Behrendtz, A. Castor, E. Forestier, D. R. Uges and S. S. de Graaf, "Vincristine in Childhood Leukaemia: No Pharmacokinetic Rationale for Dose Reduction in Adolescents," Acta Paediatrica, Vol. 92, No. 5, 2003, pp. 551-557. doi:10.1111/j.1651-2227.2003.tb02505.x

[32] A. S. Moore, R. Norris, G. Price, T. Nguyen, M. Ni, R. 
George, K. van Breda, J. Duley, B. Charles and R. Pinkerton R, "Vincristine Pharmacodynamics and Pharmacogenetics in Children with Cancer: A Limited-Sampling, Population Modelling Approach," Journal of Paediatrics and Child Health, Vol. 47, No. 12, 2011, pp. 875882. doi:10.1111/j.1440-1754.2011.02103.x

[33] C. H. Fu and K. M. Sakamoto, "PEG-Asparaginase,"
Expert Opinion of Pharmacotherapy, Vol. 6, No. 12, 2007, pp. 1977-1984. doi:10.1517/14656566.8.12.1977

[34] A. Rasheed, A. Iqtidar and S. Khan, "Hematological and Biochemical Changes in Acute Leukemic Patients after Chemotherapy," Zhongguo Yao Li Xue Bao, Vol. 17, No. 3, 1996, pp. 207-208. 